\title{
Comparison of commercial RNA extraction kits for preparation of DNA-free total RNA from Salmonella cells
}

\author{
Lydia V Rump, Benedicta Asamoah, Narjol Gonzalez-Escalona*
}

\begin{abstract}
Background: The isolation of DNA-free RNA is a crucial step in the reverse transcription PCR (RT-PCR). Every RNA extraction procedure results in RNA samples contaminated with genomic DNA, which can cause false-positive outcomes in highly sensitive applications, including a recently developed quantitative real-time PCR (RT-qPCR) assay that targets invA mRNA for the detection of live Salmonella cells. The assay of this specific mRNA can be used to indicate the presence of live, as opposed to dead, cells of Salmonella enterica in a food matrix.

Findings: We evaluated the ability of five RNA extraction kits to produce RNA preparations from exponentially growing Salmonella cells. The acceptability of the preparations for use in downstream applications such as RT-qPCR was judged in terms of the total amount of RNA recovered, the integrity of the RNA molecules, and minimal content of DNA. The five kits produced RNA preparations that differed markedly in yield, integrity of the Salmonella RNA and the amount of contaminant DNA. The greatest RNA recovery was achieved with the MasterPure kit; however, the preparation contained high levels of genomic DNA. The UltraClean extraction kit gave a low level of RNA recovery with a poor level of integrity. The RNeasy Mini, RiboPure and PureLink extraction kits produced highquality, DNA-free RNA suitable for Salmonella detection by RT-qPCR.

Conclusions: We showed that the RNeasy Mini and PureLink RNA extraction kits were the most suitable for the detection of Salmonella invA mRNA by RT-qPCR. The use of these two kits will greatly reduce the frequency of false-positive results and might allow fast RT-qPCR determination of invA mRNA produced by viable Salmonella in food samples.
\end{abstract}

\section{Background}

Commercially available RNA extraction kits are rapid, capable of high-throughput analysis and cost-effective [1]. The isolation of DNA-free RNA is crucial to the success of highly sensitive assays like RT-PCR. RNA extraction procedures frequently result in RNA preparations that are highly contaminated with genomic DNA, which often leads to false-positive RT-PCR outcomes. The presence of DNA in an RNA sample can be detected easily by an appropriate PCR test of an indicator gene. Then, if necessary, treatment of the RNA preparation with DNase I will usually eliminate, or at least substantially reduce, the content of DNA [2].

\footnotetext{
* Correspondence: narjol.gonzalez-escalona@fda.hhs.gov

Center for Food Safety and Applied Nutrition, Food and Drug

Administration, 5100 Paint Branch Parkway, College Park, MD 20740, USA
}

The RNA concentration of a sample is commonly determined via measurement of absorbance at a wavelength of $260 \mathrm{~nm}\left(A_{260}\right)$. The purity of the RNA sample can be determined using the $A_{260} / A_{280}$ ratio as a reference (a value of $\sim 2.0$ is considered "pure" RNA). However, the accuracy of this method is questionable, because protein contamination can cause an overestimation $(>50 \%)$ of RNA content $[3,4]$. Moreover, RNA is susceptible to degradation by RNases present in the sample, which can result in shorter fragments of RNA and this decrease in RNA integrity might interfere with downstream applications; e.g. microarray expression profiles [5]. Another technique commonly used to determine the concentration and extent of degradation of an RNA sample is agarose gel electrophoresis with subsequent banding pattern analysis [4]. However, this

\section{Biomed Central}


approach relies on the human eye and is prone to errors of interpretation.

There are methods that allow for the accurate estimation of RNA concentration. Modern spectrometric methods, such as spectrophotofluorimetry (Nanodrop ND-3000, Fisher Scientific), in combination with RNA RiboGreen dye (Molecular Probes, Invitrogen) can be used for ultrasensitive RNA quantification http://www. nanodrop.com/Library/art-gen-state-microsample-quantitation.pdf. Lab-on-chip technology, such as the Agilent 2100 Bioanalyzer (Agilent technologies) and Experion (Bio-Rad Laboratories) are widely used to estimate RNA quality and quantity [6]. Agilent has developed software to calculate the RNA integrity number (RIN), a qualitative assessment of RNA quality [5]. RIN values range from 1 to 10 , with 1 being the most degraded and 10 the least degraded [6].

The present study evaluated the performance of five commonly used commercial RNA extraction kits for isolating cellular RNA, using actively growing Salmonella SE5 as a model organism. The kits evaluated were: the RiboPure Bacteria Kit (Ambion), the PureLink RNA Mini Kit (Invitrogen), the UltraClean Microbial RNA Isolation Kit (MoBio, Carlsbad, CA), the RNeasy Mini Kit (Qiagen) and the MasterPure RNA Purification Kit (EPICENTRE). The kits were compared for (1) the yield of RNA, (2) the polymeric length integrity of the RNA and (3) the amount of DNA present in the RNA preparation.

\section{Methods}

Bacterial strains and media

Salmonella enterica serovar Enteritidis strain SE5 was grown overnight in Luria-Bertani (LB) medium_at $35^{\circ} \mathrm{C}$ with shaking $(250 \mathrm{rpm})$.

\section{Nucleic acid extraction}

The performance of five commercial RNA extraction kits was evaluated: RiboPure-Bacteria Kit (Ambion, Inc), PureLink RNA Mini Kit (Invitrogen), UltraClean Microbial RNA Isolation Kit (MoBio), RNeasy Mini Kit (QIAGEN) and MasterPure RNA Purification Kit (EPICENTRE Biotechnologies). The principles for RNA purification of these kits are very similar. The UltraClean and the RiboPure kits use a bead cell disruption system. Four of the kits, except the MasterPure kit, use spin-column technology and selective binding properties of silica membranes. The RNA adsorbs to the silica membrane in the presence of high concentrations of salt. Contaminants are unable to bind to the silica column and therefore pass through the column. The loaded column is washed and then any bound RNA is eluted. The MasterPure kit uses a salt-precipitation protocol, instead of a column, to purify the RNA and it captures the small RNA molecules that tend to be lost when using columns. All RNA extractions were done in triplicate $(1 \mathrm{ml}$ each) with exponentially growing SE5 cells and following the manufacturer's recommendations for each kit. The final RNA fraction was obtained by elution or suspended in $50 \mu \mathrm{l}$ of DEPC-treated water (Ambion). The treatment with DNase I (Invitrogen) was done at $37^{\circ} \mathrm{C}$ for $30 \mathrm{~min}$ and the DNase was inactivated by incubation at $65^{\circ} \mathrm{C}$ for $10 \mathrm{~min}$.

\section{Determination of RNA concentration and RNA integrity number (RIN)}

The RNA concentration in individual RNA samples was determined using the RNA Pico 6000 LabChip kit (Agilent Technologies). The LabChips were run in an Agilent 2100 Bioanalyzer following the manufacturer's instructions (Agilent). The use of the RNA Pico 6000 LabChip kit allowed determination of the RNA integrity number (RIN), an indicator of the integrity of the RNA in the sample, using 2100 Bioanalyzer Expert software [5].

\section{Determination of DNA contamination in the RNA samples} before and after treatment with DNase I

The invA mRNA levels were measured by RT-qPCR as described [7]. The invA RT-qPCR reactions were done as described [7], but without an internal control. Briefly, RT-qPCR reactions were done with the SuperScriptTM III Platinum One-Step Quantitative RT-PCR System kit essentially according to the manufacturer's instructions (Invitrogen) but with reactions scaled down to a final volume of $20 \mu \mathrm{l}$ and $\mathrm{MgCl}_{2}$ added to the master mix to a final concentration of $5 \mathrm{mM}$. The final concentration of each primer was 200 nM: (invA_176F 5'CAACGTTTCCTGCGGTACTGT-3') and invA_291R (5'-CCCGAACGTGGCGATAATT-3'). The final concentration of the probe invA_Tx_208 was $150 \mathrm{nM}$ (5'TX-CTCTTTCGTCTGGCATTATCGATCAGTACCABHQ2-3'). RT-qPCR and data analysis (in triplicate) were done with a Rotor-Gene 3000 (Corbett) real-time PCR instrument using $2 \mu \mathrm{l}$ of each RNA sample. Additionally, each RNA sample was amplified by invA qPCR to detect DNA contamination and to estimate the number of invA DNA copies present in the sample. The RTqPCR conditions were as follows: $15 \mathrm{~min}$ at $50^{\circ} \mathrm{C}$ for the generation of the cDNAs, $2 \mathrm{~min}$ at $95^{\circ} \mathrm{C}$ to activate the hot-start Taq polymerase and then 40 cycles of denaturation at $95^{\circ} \mathrm{C}$ for $15 \mathrm{~s}$, and primer annealing and extension at $60^{\circ} \mathrm{C}$ for $30 \mathrm{~s}$ (the acquisition of Texas Red emission was performed at the end of this cycle). Identical conditions were used for $\mathrm{qPCR}$ reactions. The reported efficiency of the qPCR and RT-qPCR for these primers is $0.93-0.99$ and $0.90-0.96$, respectively [7]. The term $\mathrm{Cq}$ is equivalent to the original $\mathrm{Ct}$ (threshold 
cycle) terminology [8]. A difference between the Cq values for $\mathrm{RT}$-qPCR and $\mathrm{qPCR}$ of $>4$ cycles was considered a positive result. Differences in the range 3.1 - 3.6 cycles between samples are mostly due to differences in concentration of about 10-fold (if efficiency is 90 110\%) https://www.genomics.agilent.com/CalculatorPopupWindow.aspx?CalID $=8$. For $\mathrm{Cq}$ values that dipped below this range, the RNA sample was considered inadequate for the detection of Salmonella invA mRNA.

\section{Results and discussion}

\section{Determination of RNA concentration and RIN values}

Total RNA concentrations were determined with a 2100 Bioanalyzer and the RNA 6000 Pico LabChip kit (Agilent) [1]. As expected, the highest mean level of RNA $(1.82 \pm 0.36 \mu \mathrm{g} / \mu \mathrm{l})$ was obtained using The MasterPure kit, which does not include passage through a column and, therefore, is not subject to limitations imposed by column binding capacity. The RNA yield from columnbased extraction methods depends greatly on the binding capacity of the column, which is designed primarily for small-scale RNA extractions, where this limitation has little impact. Next in order of RNA recovery were the column-based PureLink $(0.97 \pm 0.32 \mu \mathrm{g} / \mu \mathrm{l})$, RNeasy $(0.78 \pm 0.32 \mu \mathrm{g} / \mu \mathrm{l})$ and RiboPure $(0.28 \pm 0.05 \mu \mathrm{g} / \mu \mathrm{l})$ kits. The smallest RNA yield $(0.05 \pm 0.03 \mu \mathrm{g} / \mu \mathrm{l})$ was obtained with the UltraClean kit. This descending order of recovery of the column-based kits parallels the descending order of binding capacity stated by the manufacturers: PureLink (up to $1000 \mu \mathrm{g}$ ), RNeasy $(100 \mu \mathrm{g}$ ), RiboPure $(90 \mu \mathrm{g})$ and UltraClean $(60 \mu \mathrm{g})$.

The PureLink and the RNeasy kits use chemical methods to lyse the cells, whereas the RiboPure and UltraClean kits physically disrupt the bacterial cell walls by beating the cells with beads. Greater disruption would be expected to improve the RNA yield; however, the bead-based kits yielded less RNA than the others. This suggests that the different RNA yields of these kits are not due only to different extents of cell lysis.

RNA molecules are thermodynamically stable but can be digested rapidly by RNases present in the cell lysate, which could result in short RNA fragments that can compromise downstream applications [5]. RIN values for each RNA sample were obtained with a 2100 Bioanalyzer (Agilent) and an RNA 6000 Pico LabChip kit. Most of the kits extracted largely intact Salmonella RNA, as indicated by the RIN values of 8 or higher (Table 1). The exception was the UltraClean kit, which yielded RNA of lower integrity with a mean RIN value of $5.65 \pm 4.03$ (Table 1). Because of the influence of RNA integrity on downstream applications, samples with RIN values $<8$ might have a negative influence on the outcome of an experiment. However, an RNA
Table 1 Mean RNA integrity number (RIN) of total RNA extracted from exponentially growing Salmonella SE5 cells by 5 kits

\begin{tabular}{lcc}
\hline RNA extraction kit & Manufacturer & RIN \\
\hline RiboPure-Bacteria Kit & Ambion & $9.30 \pm 0.36$ \\
PureLink RNA Mini Kit & Invitrogen & $9.07 \pm 1.62$ \\
RNeasy Mini Kit & QIAGEN & $9.57 \pm 0.59$ \\
MasterPure RNA Purification Kit & EPICENTRE & $8.00 \pm 1.21$ \\
UltraClean Microbial RNA Isolation Kit & Biotechnologies & Mo Bio \\
\hline
\end{tabular}

sample could be degraded to an extent that precluded a genome-wide microarray experiment but might still deliver good RT-PCR data.

\section{RT-qPCR analysis (invA mRNA)}

RT-PCR and RT-qPCR are important tools for the detection of pathogens in foods [7,9-11]. The RTqPCR assay depends on the use of intact RNA; the higher the RNA quality, the lower the variability of the results [12]. In this study, we determined the influence of the degree of RNA integrity on the RT-qPCR mRNA detection and quantification in RNA samples extracted from exponentially growing Salmonella [7]. An RT-qPCR assay of invA mRNA in tandem with qPCR of $i n v A$ DNA was used to detect the presence of DNA in the RNA preparations produced by five RNA extraction kits and to assess the extent of its degradation by treatment with DNase I. The DNA polymerase is incapable of amplifying RNA, so the qPCR (invA DNA) results indicate the presence of DNA in the RNA samples [13].

The invA mRNA RT-qPCR and invA qPCR results are given in Tables 2 and 3, respectively, for the RNA samples obtained with the kits before and after treatment with DNase I. All of the kits yielded RNA samples containing large amounts of DNA (Table 2). After treatment with DNase I, the DNA content of the RNA samples obtained with four of the kits was reduced to levels that did not interfere with the detection of $i n v A$ mRNA (Table 3). Therefore, treatment with DNase I is absolutely required for eliminating all traces of DNA. In the case of the highest initial level of DNA contamination observed with the MasterPure kit, some traces of DNA remaining in the sample could interfere with RTqPCR assays and so this kit was excluded from the evaluation of the effect of RIN values on the RT-qPCR results.

We observed that the RIN value of a Salmonella RNA sample does not appear to be correlated with the ability to detect invA mRNA by RT-qPCR. The RNA samples produced by the UltraClean kit had the lowest RIN 
Table 2 Inability of RT-qPCR to detect invA mRNA in RNA extracts not treated with DNase I

\begin{tabular}{lcccc}
\hline RNA extraction kit & Manufacturer & $\begin{array}{c}\text { invA mRNA copies/rxn } \\
\text { RT-qPCR [Cq }]^{\mathbf{a}}\end{array}$ & $\begin{array}{c}\text { invA DNA copies/rxn } \\
\text { qPCR [Cq }]^{\mathbf{b}}\end{array}$ & $\begin{array}{c}\text { invA mRNA presence } \\
\text { (Cq qPCR - Cq RT- } \\
\text { qPCR) }\end{array}$ \\
\hline RiboPure-Bacteria & Ambion & $(1.9 \pm 1.6) \times 10^{6}[25.5 \pm 1.8]$ & $(1.8 \pm 1.8) \times 10^{6}[24.8 \pm 1.4]$ & -0.7 (Negative) \\
PureLink RNA Mini & Invitrogen & $(1.2 \pm 0.5) \times 10^{8}[18.8 \pm 0.6]$ & $(1.5 \pm 0.8) \times 10^{8}[18.5 \pm 0.7]$ & -0.3 (Negative) \\
RNeasy Mini & QIAGEN & $(7.9 \pm 2.2) \times 10^{7}[19.3 \pm 0.4]$ & $(1.1 \pm 0.3) \times 10^{8}[18.9 \pm 0.4]$ & -0.4 (Negative) \\
MasterPure RNA Purification & EPICENTRE & $(5.8 \pm 0.8) \times 10^{8}[16.4 \pm 0.2]$ & $(8.8 \pm 0.9) \times 10^{8}[15.9 \pm 0.2]$ & -0.3 (Negative) \\
UltraClean Microbial RNA & Biotechnologies & & & \\
Isolation & MoBio & $(2.2 \pm 0.6) \times 10^{8}[17.8 \pm 0.4]$ & $(3.4 \pm 0.8) \times 10^{8}[17.3 \pm 0.3]$ & -0.5 (Negative) \\
\hline
\end{tabular}

rxn, reaction.

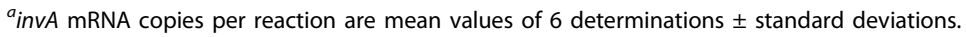

${ }^{b}$ invA DNA copies per reaction are mean values of 6 determinations \pm standard deviations.

c- If $<4$ is negative or inconclusive for invA mRNA presence due to DNA contamination.

Detection limit of the invA qRT-PCR and invA qPCR are 40 and 10 copies per reaction, respectively [7]

value, indicating a high level of RNA degradation, and contained fewer invA mRNA copies than the RNA samples produced by the other kits (Table 2). However, these numbers of invA mRNA copies might be due to the low initial concentration of RNA in the sample $(0.05$ $\pm 0.03 \mu \mathrm{g} / \mu \mathrm{l})$ and not to the quality of the RNA sample, which has been observed by others for different types of RNA samples [14]. The concentrations of RNA in the samples produced by the UltraClean kit were about 5 19-fold lower than those produced by the other kits. Accordingly, the amount of invA mRNA molecules in that sample ought to be smaller and could explain the 4 - 11-fold fewer copies observed for this kit compared to the others (Table 3). In any case, due to its low yield of total RNA and its low RIN value, the UltraClean kit is unsuitable for applications such as the detection of $i n v A$ mRNA by RT-qPCR. The RiboPure, PureLink and RNeasy kits are the most suitable for sensitive RT-qPCR assays, such as the detection of invA mRNA in Salmonella, because they yielded high average recovery levels of RNA with high RIN values and low levels of DNA.

\section{Conclusion}

Overall, this comparison showed that most of the kits tested were suitable for Salmonella RNA extraction. The greatest concentration of total RNA was obtained with the MasterPure kit; however, the sample contained high levels of genomic DNA, which interferes with invA mRNA detection by RT-qPCR. Therefore, the MasterPure kit could be most useful for assays, such as northern blot analysis, that require large amounts of RNA and are unaffected by the presence of DNA. The RIN values obtained with the RiboPure, PureLink, RNeasy and MasterPure extraction kits were within the acceptable range for RNA integrity. The UltraClean kit isolated highly degraded RNA (RIN value $<6$ ), which is unsuitable for some RNA assays. As expected, the treatment of RNA samples with DNase I after extraction appears to be absolutely required to reduce the amount of residual DNA, especially for sensitive assays like invA RT-qPCR. The RNeasy and RiboPure extraction kits produced large yields of RNA with a high degree of integrity and could be considered the kits of choice for the detection of Salmonella invA mRNA by RT-qPCR.

Table 3 Effect of DNase I treatment of RNA extracts on ability to detect invA mRNA by RT-qPCR

\begin{tabular}{|c|c|c|c|c|}
\hline RNA extraction kit & Manufacturer & $\begin{array}{c}\text { invA mRNA copies/rxn } \\
\text { RT-qPCR [Cq] }{ }^{a}\end{array}$ & $\begin{array}{l}\text { invA DNA copies/rxn } \\
\text { qPCR [Cq] }{ }^{\mathrm{b}}\end{array}$ & $\begin{array}{c}\text { invA mRNA presence } \\
\text { (Cq qPCR - Cq RT- } \\
\text { qPCR })^{\mathrm{c}}\end{array}$ \\
\hline RiboPure-Bacteria & Ambion & $(5.46 \pm 0.88) \times 10^{5}[26.5 \pm 0.9]$ & $<10[37.1 \pm 1.5]$ & 10.6 (Positive) \\
\hline PureLink RNA Mini & Invitrogen & $(7.71 \pm 1.89) \times 10^{5}[26.0 \pm 1.2]$ & $<10[37.5 \pm 1.8]$ & 11.5 (Positive) \\
\hline RNeasy Mini & QIAGEN & $(7.82 \pm 1.25) \times 10^{6}[21.5 \pm 0.5]$ & $<10[36.5 \pm 1.7]$ & 15 (Positive) \\
\hline MasterPure RNA Purification & $\begin{array}{c}\text { EPICENTRE } \\
\text { Biotechnologies }\end{array}$ & $(1.19 \pm 2.38) \times 10^{8}[18.7 \pm 1.0]$ & $(3.10 \pm 2.60) \times 10^{7}[21.5 \pm 1.2]$ & 2.8 (Negative) \\
\hline $\begin{array}{l}\text { UltraClean Microbial RNA } \\
\text { Isolation }\end{array}$ & MoBio & $(1.28 \pm 1.12) \times 10^{5}[28.6 \pm 0.6]$ & $(1.00 \pm 1.20) \times 10^{3}[33.2 \pm 1.5]$ & 4.6 (Positive) \\
\hline
\end{tabular}

rxn, reaction.

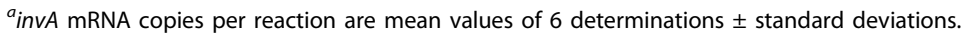

${ }^{b}$ invA DNA copies per reaction are mean values of 6 determinations \pm standard deviations.

c- If $<4$ is negative or inconclusive for invA mRNA presence due to DNA contamination.

Detection limit of the invA qRT-PCR and invA qPCR are 40 and 10 copies per reaction, respectively [7]. 


\section{Acknowledgements}

The authors thank Brenda Kroft, Eric W. Brown and Anthony D. Hitchins for their helpful comments.

\section{Authors' contributions}

LVR did most of the RNA extractions, participated in the experimental design, and production of the draft of the manuscript. BA did some RNA extractions; participated in the experimental design, and production of the draft of the manuscript. NGE conceived the study, participated in the experimental design and coordination, did the RT-qPCR assays, and participated in production of the draft of the manuscript. All authors have read and approved the final manuscript.

\section{Competing interests}

The authors declare that they have no competing interests.

Received: 30 April 2010 Accepted: 27 July 2010 Published: 27 July 2010

\section{References}

1. Jahn $C E$, Charkowski AO, Willis DK: Evaluation of isolation methods and RNA integrity for bacterial RNA quantitation. J Microbiol Methods 2008, 75:318-324

2. Vanecko S, Laskowski MS: Studies of the specificity of deoxyribonuclease I. II. Hydrolysis of oligonucleotides carrying a monoesterified phosphate on carbon 3'. J Biol Chem 1961, 236:1135-1140.

3. Baelde HJ, Cleton-Jansen AM, van BH, Namba M, Bovee JV, Hogendoorn PC High quality RNA isolation from tumours with low cellularity and high extracellular matrix component for CDNA microarrays: application to chondrosarcoma. J Clin Pathol 2001, 54:778-782.

4. Bustin SA, Benes V, Nolan T, Pfaffl MW: Quantitative real-time RT-PCR-a perspective. J Mol Endocrinol 2005, 34:597-601.

5. Schroeder A, Mueller O, Stocker S, Salowsky R, Leiber M, Gassmann M, Lightfoot S, Menzel W, Granzow M, Ragg T: The RIN: an RNA integrity number for assigning integrity values to RNA measurements. BMC Mol Biol 2006, 7:3.

6. Mueller O, Hahnenberger K, Dittmann M, Yee H, Dubrow R, Nagle R, Ilsley D: A microfluidic system for high-speed reproducible DNA sizing and quantitation. Electrophoresis 2000, 21:128-134.

7. Gonzalez-Escalona N, Hammack TS, Russell M, Jacobson AP, De Jesus AJ, Brown EW, Lampel KA: Detection of live Salmonella sp. cells in produce by a TaqMan-based quantitative reverse transcriptase real-time PCR targeting invA mRNA. Appl Environ Microbiol 2009, 75:3714-3720.

8. Bustin SA, Benes V, Garson JA, Hellemans J, Huggett J, Kubista M, Mueller R, Nolan T, Pfaffl MW, Shipley GL, Vandesompele J, Wittwer CT: The MIQE guidelines: minimum information for publication of quantitative realtime PCR experiments. Clin Chem 2009, 55:611-622.

9. Scipioni A, Bourgot I, Mauroy A, Ziant D, Saegerman C, Daube G, Thiry E: Detection and quantification of human and bovine noroviruses by a TaqMan RT-PCR assay with a control for inhibition. Mol Cell Probes 2008, 22:215-222.

10. Stevenson J, Hymas W, Hillyard D: The use of Armored RNA as a multipurpose internal control for RT-PCR. J Virol Methods 2008, 150:73-76.

11. Jacobsen CS, Holben WE: Quantification of mRNA in Salmonella sp seeded soil and chicken manure using magnetic capture hybridization RT-PCR. Journal of Microbiological Methods 2007, 69:315-321.

12. Fleige $S$, Pfaffl MW: RNA integrity and the effect on the real-time qRTPCR performance. Mol Aspects Med 2006, 27:126-139.

13. Del Aguila EM, Dutra MB, Silva JT, Paschoalin VM: Comparing protocols for preparation of DNA-free total yeast RNA suitable for RT-PCR. BMC Mol Biol 2005, 6:9.

14. Fleige $S$, Walf $V$, Huch S, Prgomet C, Sehm J, Pfaffl MW: Comparison of relative mRNA quantification models and the impact of RNA integrity in quantitative real-time RT-PCR. Biotechnol Lett 2006, 28:1601-1613.

doi:10.1186/1756-0500-3-211

Cite this article as: Rump et al: Comparison of commercial RNA extraction kits for preparation of DNA-free total RNA from Salmonella cells. BMC Research Notes 2010 3:211.

\section{Submit your next manuscript to BioMed Central and take full advantage of:}

- Convenient online submission

- Thorough peer review

- No space constraints or color figure charges

- Immediate publication on acceptance

- Inclusion in PubMed, CAS, Scopus and Google Scholar

- Research which is freely available for redistribution

Submit your manuscript at www.biomedcentral.com/submit 